\title{
Echoic memory and voice quality: Recency recall is not enhanced by varying presentation voice
}

\author{
OLGA C. WATKINS and MICHAEL J. WATKINS \\ Princeton University, Princeton, New Jersey 08544
}

\begin{abstract}
Three experiments explored the effects on immediate recall of varying voice of presentation. Experiment 1 showed that the free-recall recency effect was not enhanced by presenting list words alternately in a male and a female voice. Experiment 2 replicated this result and also showed that recall of a given recency item from such a list was no more probable when the subjects were informed immediately following presentation that they need not recall the words presented in the other voice. Experiment 3 replicated previous findings of a reduction in the "suffix effect" when presentation voice is changed for the suffix item. The relation of this result to those of Experiments 1 and 2 is discussed.
\end{abstract}

The idea that the last part of an ongoing (or recently terminated) spoken message is represented in an auditory or echoic memory (Crowder \& Morton, 1969; Neisser, 1967) provides a useful interpretation of a number of experimental findings. Its account of the modality effect-the greater recency effect in the immediate recall of an auditorily as opposed to a visually presented list-illustrates the point: Following auditory presentation, the most recent items are represented in echoic memory, and this representation is used to aid recall.

Precisely how echoic memory should be characterized has been the subject of much research. One approach to the question involves the suffix effect. By suffix effect is meant the selective reduction in the recency effect obtained when an auditorily presented list is followed by an additional auditory item that is nominally irrelevant to the subject's task (Crowder, 1969; Dallett, 1965). The effect is usually attributed to the erasure of echoic information, and the precise conditions under which it occurs have been explored as a means of inferring the nature of echoic memory. For example, it has been found that it makes little if any difference to the magnitude of the suffix effect whether the suffix item is the digit 0 , the instruction "recall," or the meaningless sound obtained by playing a taped word backward (Crowder \& Raeburn, 1970; Morton, Crowder, \& Prussin, 1971). On the other hand, no suffix effect occurs when a list of verbal items is followed by a nonverbal item such as a tone (Crowder, 1971). From these findings, it has been inferred that echoic memory of spoken material is insensitive to meaning but highly sensitive to the speech-nonspeech distinction.

This research was supported by the National Institute of Mental Health Grant 1-RO1-MH31674.
The concern of the present paper is with the properties of echoic memory within the speech domain. Morton et al. (1971, Experiments 14 and 15; see also Elmes, 1974) have found that the suffix effect is reduced when the suffix is presented in a different voice from that of the list items. An obvious interpretation of this finding is that echoic memory is sensitive to voice quality such that the echoic representation of an item presented in one voice is overwritten or interfered with more by a subsequent item presented in the same voice than by one presented in a different voice.

If this interpretation is valid, then presumably it should be possible to increase the contribution of echoic memory to recall by varying the voice of presentation of the to-be-remembered items. For instance, there should be a greater echoic representation when the successive items of a list are presented alternately in a male and a female voice rather than all in one voice. Thus, the item presented second from the end of the list will be followed by an item in a different voice, rather than by one in the same voice; the item presented third from the end will be followed by one in a different voice and by one in the same voice, rather than by two in the same voice; and so on. The net result should be that the recency items will be better represented in echoic memory, and hence the recency effect will be more pronounced. This prediction was tested in the first experiment.

\section{EXPERIMENT 1}

Subjects were presented with a series of word lists for immediate free recall. Within a list, the words occurred either all in the same voice or alternately in a male and a female voice. Of interest was whether recall of the last few, or "recency," items of a list would be better for the two-voice lists. 


\section{Method}

Materials and Design. Twenty-four lists of 16 two-syllable words were constructed from the Toronto word pool. Four were practice lists, and 20 were experimental lists. There were two conditions: In the one-voice condition, the list words occurred all in the same voice (either male or female), and in the two-voice condition they occurred alternately in a male and a female voice. All subjects received 12 lists, including 2 practice lists, in each condition. In the one-voice condition, half of the lists were in a male voice and half in a female voice. In the two-voice condition, half of the lists started with a male-voiced word and half with a femalevoiced word. The lists were recorded on tape at a rate of $1 \mathrm{word} / \mathrm{sec}$. A nonverbal acoustic signal given $1 \mathrm{sec}$ after the last word indicated the end of a list.

All subjects heard the same set of lists presented in the same order, which was random with respect to condition. List condition varied between subjects such that each list occurred in the onevoice condition for half of the subjects and in the two-voice condition for the other half. There were thus two complementary recordings of the lists.

Subjects. Sixteen university students were paid for participating.

Procedure. Subjects were tested either individually or in pairs. They heard a series of word lists from a tape recorder. The words within a list occurred either all in a male voice, all in a female voice, or alternating in a male and a female voice. The order of conditions was irregular, but the subjects were informed of each list's condition before its presentation. On hearing the recall signal, the subjects wrote down as many of the words as they could remember. They were told that they were free to recall the words in any order, except that if they remembered the words from the end of the list then those should be written down first. The purpose of these instructions was to encourage the use of whatever echoic representation might be available. No time limits were imposed; the next list was presented when the subjects were ready.

\section{Results and Discussion}

A preliminary analysis indicated that recall did not depend to any statistically significant extent on whether presentation was in a male or a female voice, and so the data were pooled across this variable. The resulting serial position functions are shown in Figure 1.

It is clear that the prediction that recency recall would be greater in the two-voice condition was not supported. The mean probability of a recency item

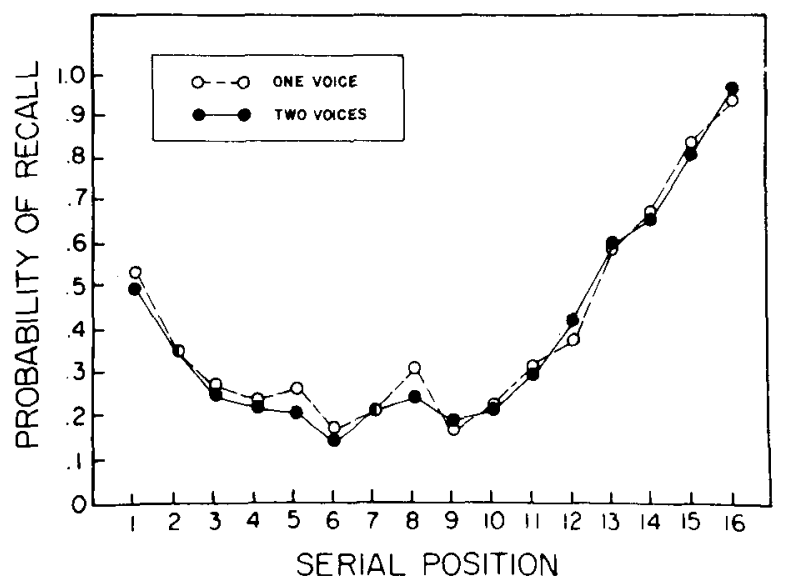

Figure 1. Free recall of one- and two-voice lists. (one from Serial Positions 9-16) being recalled was identical for the two conditions (.46). It appears, then, that the recallability of an item from a spoken list is reduced by the presentation of a subsequent list item to an extent that is independent of whether the two items are presented in the same voice or in different voices. In terms of the conventional view that the recency effect with spoken lists results (in part, at least) from the use of echoic memory, the implication is that echoic interference or erasure is not voice specific.

The conclusion that echoic interference is not voice specific rests on the null hypothesis, and so should be drawn with caution. It could be argued that one reason we failed to find a recency advantage in the two-voice condition is that, although at the time of the recall signal there was more echoic information available following a two-voice than a one-voice list, this additional information faded before the subject had a chance to make use of it. This possibility is supported by Darwin, Turvey, and Crowder's (1972) finding that, following simultaneous presentation of three short lists of items over spatially defined channels, subjects recalled more items from a particular channel when cued immediately after presentation to recall only those items from that channel than they did when cued to recall all items. Darwin et al. concluded that immediately after presentation, more echoic information was available than the subject was able to use. To determine whether the present procedures resulted in a comparable state of affairs, we conducted a second experiment that was similar to the first but included an additional condition in which two-voice lists were followed by a cue for recall of only those words presented in one particular voice. If in Experiment 1 there was in fact additional echoic information following a two-voice list that was lost before it could be used, then presumably it should be made manifest when only a subset of the items is to be recalled.

\section{EXPERIMENT 2}

\section{Method}

Materials and Design. The word lists were the same as for Experiment 1, except that there were 48 of them. Eight of these lists were used for practice. As in the first experiment, the words within a list occurred either all in the same (male or female) voice, or alternately in a male and a female voice. Following the two-voice lists, subjects were cued to recall either all words or only those presented in one of the voices. For the one-voice lists, subjects always tried to recall all words.

Apart from the practice lists, each subject received 10 lists in the one-voice condition and 30 in the two-voice condition. Half of the one-voice lists were presented in a male voice and half in a female voice. Of the two-voice lists, half started with a male-voiced word and half with a female-voiced word. For each subject, 10 of the two-voice lists were followed by a cue to recall only the male-voiced words, 10 by a cue to recall only the femalevoiced words, and 10 by a cue to recall all of the words. Thus, 
in terms of experimental design, there were four conditions with 10 lists in each. The lists were recorded on tape at a rate of $1 \mathrm{word} / \mathrm{sec}$. They were presented in the same order to all subjects, but, by rotating conditions across four subject groups of equal size, each list occurred in the four conditions an equal number of times. The ordering of conditions was random.

In the practice session, two lists were given in each condition.

Subjects. Twenty university undergraduates took part for pay.

Procedure. Subjects were tested individually or in pairs. As in Experiment 1, they heard a series of word lists, with the words of some of the lists occurring all in the same voice (either male or female) and those of others alternating between a male and a female voice. Prior to the presentation of each list, subjects were told whether the words would be in one or in two voices. For the two-voice lists, subjects did not know the recall requirement until a visual cue was given $1 \mathrm{sec}$ after the last item. The cue consisted of a card displaying the letter $M$ (for the recall of male-voiced words), $\mathrm{F}$ (for female-voiced words), or A (for all words). For the one-voice lists, the cue was always the letter A. Responses were written on a separate sheet for each list. As in Experiment 1, subjects were told that they were free to recall the cued words in any order, except that they should begin with the words from toward the end of the list. They were also told that, when cued to recall the words of just one voice in a twovoice list, they should omit only those words that they were sure had occurred in the other voice; any words they were unsure about should be written down with question marks alongside them.

\section{Results and Discussion}

As in Experiment 1, the probability of a word being recalled did not vary to any significant extent with the voice in which it was presented. The data were therefore combined across this variable. It should be noted that combining the data for the two partialreport conditions ("recall male-voiced words" and "recall female-voiced words") reduces the four conditions by which the experimental design was structured to the three conditions of theoretical interest. Since there are twice as many lists in the combined partial-report condition, the total number of observations per serial position is the same as for the other two conditions. The serial position functions for all three conditions-one voice, two-voice full report, and two-voice partial report-are given in Figure 2.

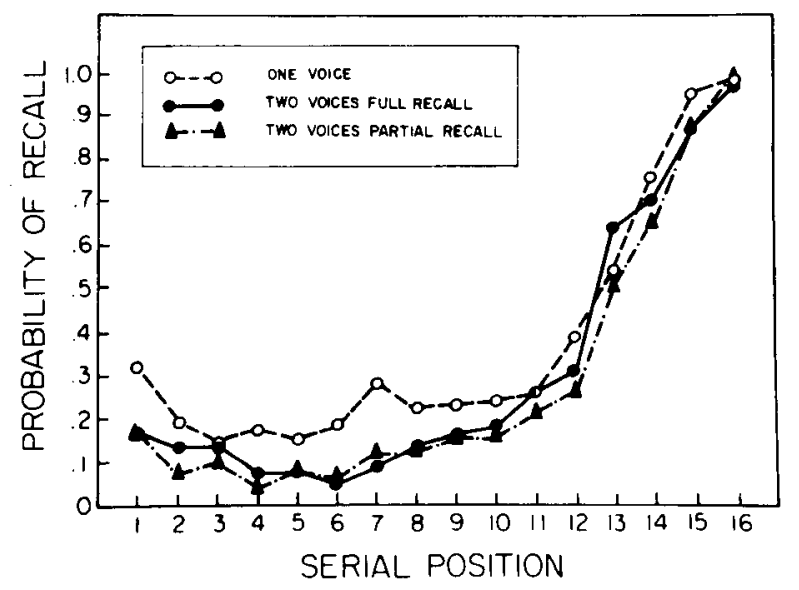

Figure 2. Free recall of one-voice, two-voice full recall, and two-voice partial recall lists.
The first thing to note is that the results replicate those of Experiment 1, in that there was a lack of a recency advantage for the two-voice full-report lists relative to one-voice lists. Indeed, the mean probability of recalling an item from the second half of the list was slightly lower for the two-voice full-report lists (.52) than for the one-voice lists (.54).

Now to the main question addressed by the present experiment: Does a recency advantage for a two-voice list arise under conditions of partial report? Once again, the results are clear: The mean probability of recalling a recency item (i.e., one from the second half of the list) was lower for the partial-report condition (.48) than for the one-voice condition (.54). Thus, there was no evidence for two voices being better than one.

It is unlikely that the failure of this two-voice partial-report procedure to facilitate recency recall was the result of the subjects having difficulty in discriminating between the voices at the time of recall. Question marks indicating the subjects' uncertainty about their responses were appended to less than $4 \%$ of correct responses. Less than $10 \%$ of the words presented in the noncued voice were recalled, and, of these, $17 \%$ were marked as uncertain. Thus, although the partial-report instruction was not entirely successful in restricting recall to words presented in the cued voice, it was sufficiently successful to ensure that any delay in the recall of words in this condition was substantially less than in the one-voice condition. And yet, there was no improvement in recency recall.

A final comment concerns the recall of prerecency items. Although not of direct concern to the present purposes, it is perhaps worth noting that the proportion of prerecency words recalled was substantially higher for one-voice lists $(.21)$ than for two-voice lists (.11 and .10 for the full-report and partial-report conditions, respectively). This difference may be related to Tulving and Colotla's (1970) finding of a higher level of prerecency recall when the words within a list were all taken from one language rather than from two or three languages. One interpretation is that words that are homogeneous in some prominent respect are more easily organized than are words that are heterogeneous. This suggestion is, of course, speculative, and it is tempered by the lack of any comparable prerecency difference in Experiment 1 .

\section{EXPERIMENT 3}

The results of Experiments 1 and 2 give no support to the notion that the echoic representation of a recently presented word is less vulnerable to the occurrence of a subsequent word if the latter is in a different voice. In this respect, our results appear contrary to the finding that the suffix effect is reduced 
when the list and suffix items are presented in different voices (Morton et al., 1971). Why should changing voice reduce the suffix effect but not the interference from subsequent list items?

Before speculating on this point, we describe an experiment designed to check that a change in voice would, in fact, reduce the suffix effect with the words used in Experiments 1 and 2 as the to-be-remembered items. Morton et al. (1971) used digits, and it is conceivable that their findings would not occur with words. Also, by using words rather than digits, we could check another potentially critical difference between Experiments 1 and 2 and those of Morton et al.: Our experiments involved a free-recall procedure in which performance depended upon only item information, whereas the Morton et al. study involved a serial-recall procedure in which performance depended upon both item and position information. Thus, it is possible that changing voice for the suffix item reduces the loss of position information but not item information. To test this possibility, Experiment 3 used a serial-recall procedure with the data scored twice: once with credit given only for recalled words that were correctly positioned, and once with credit given for all recalled words, regardless of whether they were assigned to their correct positions.

\section{Method}

Materials and Design. Forty-two eight-word lists were formed from the same source as for Experiments 1 and 2. Six were used for practice and 36 for the experiment proper. There were three conditions, defined in terms of the recall signal: In the control condition, it was a nonverbal acoustic signal; in the same-suffix condition, it was the word "recall" spoken in the same voice as the list items; and, in the different-suffix condition, it was the word "recall" spoken in a voice of the opposite sex to that of the list items. For a given subject, there were, apart from the practice lists, 12 lists in each of the three conditions, with 6 presented in a male voice and 6 in a female voice. All subjects were presented with the same six blocks of six lists in the same order. Voice of presentation alternated between blocks, and each condition occurred once in the first three blocks and once in the second three blocks. By adopting a Latin square arrangement for the first three blocks and repeating it for the second, block condition was rotated across three equal groups of subjects so that, overall, each block occurred in each condition an equal number of times.

The lists were presented from a tape recorder at a rate of 1 word/sec with the recall signal occurring $1 \mathrm{sec}$ after the last list item. Care was taken to avoid any unintended systematic differences between conditions in the way the lists and the suffixes were recorded. To this end, the lists and recall signals were recorded on separate tracks. Although the recall signal for each list was changed between subject groups, the lists themselves were recorded only once; consequently, there could be no confound between the way the lists were recorded and condition. Also, to ensure that the way the suffixes were recorded did not confound with condition, the person adding the suffix to a given list was unaware of the voice in which the list had been recorded and, hence, of the experimental condition. Specifically, one person listened to the list items on headphones and visually signaled to the person adding the suffix when to do so. The order in which the suffixes were added was random. For presentation to the subjects, the two tracks were channeled through a single speaker.
Subjects. Thirty-six university students took part for pay.

Procedure. Subjects were tested in groups of up to four persons. They heard a series of eight-word lists from a tape recorder, and, after each list, recalled as many of the words as they could, in order. Each sheet of their response booklets was ruled with a column of eight lines, and subjects began recall by entering the first word on the top line and ended with the last word on the bottom line. They indicated with a cross any word that they could not recall before proceeding to the next line, and no backtracking was allowed. Subjects were told in advance the voice of presentation and the nature of the recall signal for each successive block of lists. No time limits were imposed, and the next list was presented when all subjects were ready.

\section{Results and Discussion}

The data were scored twice, once with an item-inposition criterion and once with an item criterion. With the former, credit was given for only those words assigned to the correct input position; with the latter, credit was given for all list words recalled, regardless of their assigned positions. Figure 3 summarizes the data obtained with both the item-inposition criterion (left-hand panel) and the item criterion (right-hand panel). Each panel shows the serial position function for each of the three conditions, with data collapsed across presentation voice.

The first thing to note is that, regardless of scoring criterion, a substantial suffix effect occurred for both the same-voice and different-voice conditions. For statistical purposes, we define the suffix effect as the decrement in recall at the last position relative to that at earlier positions. In other words, the magnitude of the suffix effect is indexed by the control-oversuffix advantage for Serial Position 8 minus the average control-over-suffix advantage for Serial Positions 1-7. So defined, the effect for both the same-voice and different-voice suffixes was significant with the item-in-position criterion $[\mathrm{t}(35)=7.80$ and 3.75 , respectively] and also with the item criterion $[\mathrm{t}(35)=4.75$ and 2.77 , respectively $](\mathrm{p}<.01$ in all cases).

Of more interest to the present concern is the effect of the different-voice suffix relative to that of the same-voice suffix. Overall, recall was reduced less by

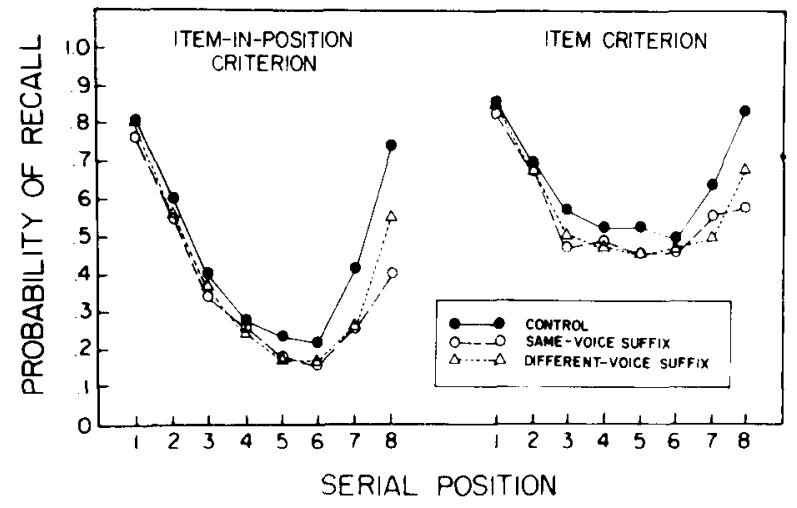

Figure 3. The suffix effect with same-voice and different-voice suffixes. 
the different-voice suffix than by the same-voice suffix. Although small, this overall advantage of switching voice was statistically significant with both criteria $[\mathrm{t}(35)=2.60, \mathrm{p}<.01$, with the item-inposition criterion; $\mathrm{t}(35)=2.31, \mathrm{p}<.02$, with the item criterion]. More specifically, the advantage of switching voice for the suffix item appeared to be localized entirely at the last serial position. Thus, the "suffix effect," as here defined, was significantly smaller in the different-voice condition, both with the item-in-position criterion $[\mathrm{t}(35)=4.17, \mathrm{p}<.01]$ and with the item criterion $[\mathrm{t}(35)=2.21, \mathrm{p}<.02]$.

In short, Experiment 3 shows that the reduced effect of a different-voice suffix reported by Morton et al. (1971) occurs with words as the memory items and regardless of whether the scoring criterion requires that the recalled items be assigned to their proper positions. And so, we return to the question of why changing voice reduces the suffix effect but did not, in Experiments 1 and 2, appear to reduce the interfering effects of the memory items themselves.

The interpretation we tend to favor is that a voice change for the suffix enables the subject to give it less attention. If the subject is able to capitalize on a difference in voice quality to help him to ignore the suffix, then presumably the list items will suffer less interference. Although a different-voice suffix might not be as easy to ignore as would different-voiced information presented simultaneously with the to-beremembered items (cf. Treisman, 1964), to the extent that it can be ignored more successfully than a samevoice suffix, it should presumably have a smaller effect on the list items. Note that such a strategy on the part of the subject has to do with study rather than recall and consequently it would have been of no value in Experiments 1 and 2, in which subjects could not profit by ignoring items during study.

We should note that there are other ways of reconciling the results of Experiment 3 with those of Experiments 1 and 2, and two of them are worth mentioning. The first is that in Experiments 1 and 2 alternating presentation voice may in fact have resulted in less echoic interference of the recency items, but the effect may have been offset by an adverse effect on the subjects' ability to study. Second, the lack of an effect of alternating the presentation voice in Experiments 1 and 2 may reflect level of recall. Note that the effect of switching voice in Experiment 3 was localized at the very last position, and end-of-list items are produced with a high probability under conditions of free recall. An implication of this interpretation is that an end-of-list advantage for the two-voice lists should arise if performance is reduced by delaying recall with a silent distractor task (cf. Watkins \& Watkins, in press, Experiment 5) or by requiring subjects to start recall with items from the beginning of the list (cf. Craik, 1969).

\section{SUMMARY AND CONCLUSIONS}

We conclude that the recall of recently spoken items is not enhanced by varying voice of presentation. In Experiment 1 the recency effect obtained with a free-recall procedure was no greater when item presentation was alternated between a male and a female voice than when all items were presented in the same voice. In Experiment 2 the recency items of two-voice lists were no more likely to be recalled then those of one-voice lists, even when the subjects were cued at the beginning of the recall interval to write down the items presented in only one of the voices. Perhaps the simplest interpretation of this finding is that echoic memory-or, indeed, whatever form of memory is assumed to underlie recall of recent, spoken items-is not "structured" or "organized" with respect to voice quality. Findings of a reduction in the suffix effect when the suffix item is presented in a different voice from the list items (Morton et al., 1971; and replicated here in Experiment 3) can be reconciled with this interpretation by assuming that voice change results, not in reduced erasure of echoic information, but rather, in a reduction in the attention given to the suffix item at the time of its presentation.

\section{REFERENCES}

CraIK, F. I. M. Modality effects in short-term storage. Journal of Verbal Learning and Verbal Behavior, 1969, 8, 658-664.

Crowder, R. G. Improved recall for digits with delayed recall cues. Journal of Experimental Psychology, 1969, 82, 258-262.

Crowder, R. G. Waiting for the stimulus suffix: Decay, delay, rhythm, and readout in immediate memory. Quarterly Journal of Experimental Psychology, 1971, 23, 324-340.

Crowder, R. G., \& Morton, J. Precategorical acoustic storage (PAS). Perception \& Psychophysics, 1969, 5, 365-373.

Crowder, R. G., \& Raeburn, V. P. The stimulus suffix effect with reversed speech. Journal of Verbal Learning and Verbal Behavior, 1970, 9, 342-345.

DalletT, K. M. "Primary memory": The effects of redundancy upon digit repetition. Psychonomic Science, 1965, 3, 237-238.

Darwin, C. J., Turvey, M. T., \& Crowder, R. G. An auditory analogue of the Sperling partial report procedure: Evidence for brief auditory storage. Cognitive Psychology, 1972, 3, 255-267.

Ermes, D. G. Isolation of items and the stimulus suffix effect. Memory \& Cognition, 1974, 2, 345-348.

Morton, J., Crowder, R. G., \& Prussin, H. A. Experiments with the stimulus suffix effect. Journal of Expreimental Psychology Monograph, 1971, 91, 169-190.

Neisser, U. Cognitive psychology. New York: Appleton-CenturyCrofts, 1967.

Treisman, A. M. Monitoring and storage of irrelevant messages in selective attention. Journal of Verbal Learning and Verbal Behavior, 1964, 3, 449-459.

Tulving, E., \& Colotla, V. Free recall of trilingual lists. Cognitive Psychology, 1970, 1, 86-98.

Watkins, O. C., \& Watkins, M. J. The modality effect and echoic persistence. Journal of Experimental Psychology: General, in press. 